ISBN 978-93-86878-07-6

8th International Conference on Agricultural, Environment, Biology and Medical Sciences

(AEBMS-2017)

Dec. 21-22, 2017 Dubai (UAE)

\title{
The Common Bacterial Infections in Patients with Leg or Hand Infections
}

\author{
Khalili M*, Karimi Ghezeli Z \\ Maryam Khalili* (corresponding author), Department of Critical Care Nursing, Faculty of Critical Care Nursing, \\ University Medical Science, Tehran, Iran. (Email: khalili.ma923@GMAIL.COM ) \\ Zahra Karimi Ghezeli, Department of Pharmaceutical Chemistry, Faculty of Pharmaceutical Chemistry, \\ Pharmaceutical Sciences Branch, Islamic Azad University, Tehran, Iran (IAUPS) \\ (e-mail: sandrakarimi20@gmail.com)

\begin{abstract}
The aim of this study was to determine the common bacteria involved in leg or hand infections. The documentary data of 91 patients with leg or hand inflammation were collected and statistically studied using descriptive statistics. Our findings indicated that the ratio of female to male was 0.47 (Figure I). Age mean was Enterobacter infection were higher than other types of bacterial infections.
\end{abstract} \\ 41.75 and 79.34 years old in females and males, respectively (Figure II). Staphylococcus aureus and
}

Keywords: Bacterial infection, Leg, Hand, Infection.

\section{Introduction}

Hand or leg infections, are inflammatory conditions caused by an invasive pathogen, usually bacteria. Inflammations may have symptoms such as swelling; rash and pain on pressure. Infections of the hand or leg are often initially caused by seemingly trivial injuries. Germs then penetrate via the lymph system, causing localised inflammation and ulceration. Infection can be either mono- or polymicrobial, with a wide variety of potential pathogens[1]. Multiresistant gram-negative bacteria are the prime mover of nosocomial infections[2]. Healthcare-associated infections (HCAI) represent up to $50 \%$ of all infections among patients admitted from the community[3].

The factors to consider in antibiotic selection include the severity of the infection, the presence of peripheral vascular disease, and the possibility of drug-resistant organisms in the infection[4]. Infection of foot ulcers is a common, often severe and costly complication in diabetes[5]. The most common site of hand infections is subcutaneous tissue and the most common mechanism is trauma [6]. The aim of this study was to determine the common bacteria involved in leg or hand infections.

\section{Materials and Methods}

The documentary data of 91 patients with leg or hand inflammation were collected and statistically studied using descriptive statistics.

\section{Results}

Our findings indicated that the ratio of female to male was 0.47 (Figure I). 


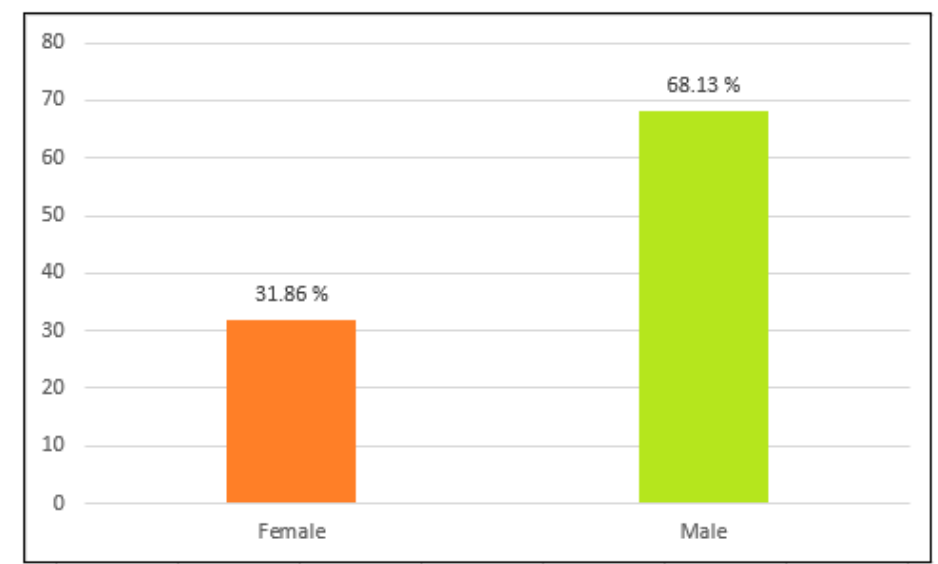

Fig. 1. Percentage of female and male patients with hand or leg infections.

Age mean was 41.75 and 79.34 years old in females and males, respectively (Figure II).

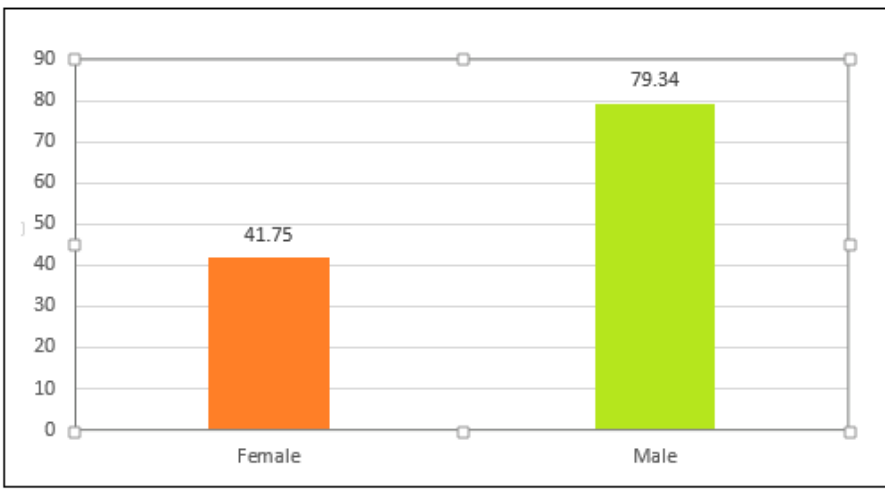

Fig. 2 Age mean in male and female patients.

Figure III shows the bacterial infections in patients with leg or hand infections; according to which, Staphylococcus aureus and Enterobacter infection were higher than other types of bacterial infections.

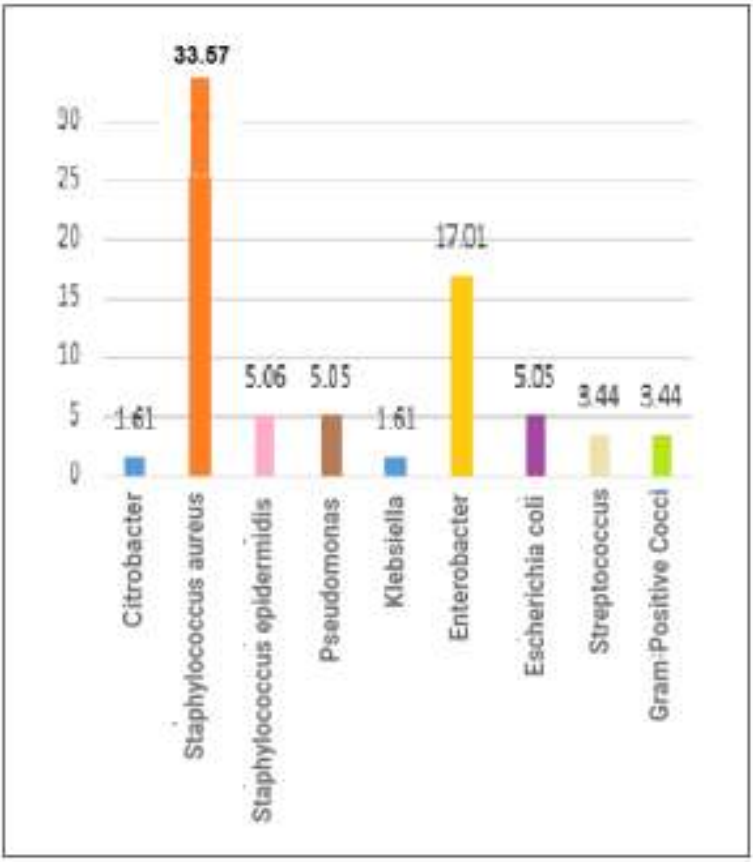

Fig. 3 . The bacterial infections in patients with leg or hand infections. 


\section{Discussion}

Our findings indicated that Staphylococcus aureus and Enterobacter infections were higher than other types of bacterial infections in patients with leg or hand infections. In line with our finding it has been shown that Staphylococcus aureus is one of the most common nosocomial pathogens which can cause a broad spectrum of infections [7].

Staphylococcus aureus is associated with various infections ranging from skin and soft tissues such as surgical site infections and abscesses to lower respiratory tracts and bloodstream[13=8].

Chronic wounds are colonized by many different bacteria. The detection rate for S. aureus has regressed by $17.1 \%$ over the past decade [15=9].

Staphylococcus aureus and Pseudomonas aeruginosa are the most common bacteria isolated from chronic wounds. They can express virulence factors and surface proteins affecting wound healing. The co-infection of S. aureus and P. aeruginosa is more virulent than single infection [10].

Venous leg ulcers are the most common cause of chronic leg wounds, accounting for up to $70 \%$ of all chronic leg ulcers and carrying with them a significant morbidity, especially for elderly patients, Chronic nonhealing wounds of the lower extremities are susceptible to microbial invasion and can lead to serious complications, such as delayed healing, cellulitis, enlargement of wound size, debilitating pain, and deeper wound infections causing systemic illness. treatment measures are often required, in addition to systemic and topical antibiotics, such as the application of wound bandages, compression therapy, and wound debridement, which can hasten clearance of the infection and help to promote healing[11].

Infections of the hand are commonly encountered in general practice. Delay in diagnosis increases the risk of tissue loss and functional impairment. Staphyloccocal infections are most common, but polymicrobial infections are often seen in immunocompromised patients. The outcome of a hand infection is related to how early it is diagnosed and initially treated. There is very little spare tissue in the hand and any destruction is devastating[12].

Enterobacter is also common bacterium observed in isolated from the finger tips of 13.3 percent of hospital personnel while they were working in the wards [13] which can be transmitted to patents as well.

\section{Conclusion}

Staphylococcus aureus and Enterobacter infections were higher than other types of bacterial infections in patients with leg or hand infections.

\section{Acknowledgment}

We appreciate all who helped us to exert this study.

\section{References}

[1] Charles PG, Uçkay I, Kressmann B, Emonet S, Lipsky BA. The role of anaerobes in diabetic foot infections. Anaerobe. 2015;34:8-13

[2] Ghodhbane H, Elaidi S, Sabatier JM, Achour S, Benhmida J, Regaya I. Bacteriocins active against multi-resistant gram negative bacteria implicated in nosocomialinfections.Infect Disord Drug Targets. 2015;15(1):2-12

[3] Cardoso T, Almeida M, Carratalà J, Aragão I, Costa-Pereira A, Sarmento AE, et al. Microbiology of healthcareassociated infections and the definition accuracy to predict infectionby potentially drug resistant pathogens: a systematic review.BMC Infect Dis. 2015;15:565.

[4] Cunha BA. Antibiotic selection for diabetic foot infections: a review.J Foot Ankle Surg. 2000;39(4):253-7. Review.

[5] Richard JL, Lavigne JP, Sotto A. Diabetes and foot infection: more than double trouble.Diabetes Metab Res Rev. 2012;28 Suppl 1:46-53.

[6] Osterman M, Draeger R, Stern P. Acute hand infections.

J Hand Surg Am. 2014;39(8):1628-35.

[7] Rahimi F. Characterization of Resistance to Aminoglycosides in Methicillin-Resistant Staphylococcus aureus Strains Isolated From a Tertiary Care Hospital in Tehran, Iran. Jundishapur J Microbiol. 2016;9(1):e29237.

[8] Sabouni F, Ranjbari R, Pourakbari B, Mahmoudi S, Teymuri M, Ashtiani MT, et al. Staphylococcus aureus infections in children in an Iranian referral pediatric hospital. J Prev Med Hyg. 2013 Dec;54(4):205-7. 
[9] Jockenhöfer F, Chapot V, Stoffels-Weindorf M, Körber A, Klode J, Buer J,et al. Bacterial spectrum colonizing chronic leg ulcers: a 10-year comparison from a German woundcare center. J Dtsch Dermatol Ges. 2014;12(12):1121-7.

[Article in English, German]

[10] Serra R, Grande R, Butrico L, Rossi A, Settimio UF, Caroleo B,et al. Chronic wound infections: the role of Pseudomonas aeruginosa and Staphylococcus aureus. Expert Rev Anti Infect Ther. 2015;13(5):605-13.

[11] Pugliese DJ. Infection in Venous Leg Ulcers:

Considerations for Optimal Management in the Elderly. Drugs Aging. 2016;33(2):87-96.

[12] Chong AKS, Puhaindran ME, Lim AYT, Looi KP.

Common bacterial infections of the hand.Singapore Med J 2006; 47(4) : 340

[13] Panhotra BR, Bhardwaj G, Naqash HU, Desai B. Zentralbl Hyg Umweltmed. Isolation and survival of gentamicin resistant Enterobacter aerogenes on finger tips of hospital personnel. 1989 Jun;188(3-4):331-5. 